\title{
A viability criterion for computer system development projects
}

\author{
J. Mende \\ Department of Accounting, University of the Witwatersrand, Johannesburg
}

\begin{abstract}
A manager facing the decision whether to proceed with a proposed computer system development project needs to determine whether its benefits are worth more than its costs. This can be done by applying a simple mathematical formula to calculate the project's 'net worth', as the sum of the annual benefits obtainable during the system's life span, less its development costs. The formula recognizes that a system's annual benefit, comprising enhanced informational value plus reduction in data processing cost, will change as a result of obsolescence, cost of capital, organizational growth and learning.

S. Afr. J. Bus. Mgmt. 1984, 15: $144-149$
\end{abstract}

Voordat 'n bestuurder kan besluit of daar met die ontwikkelingsprojek van 'n voorgestelde rekenaarstelsel voortgegaan moet word, is dit nodig om vas te stel of die beoogde voordele daarvan groter sal wees as die koste daaraan verbonde. Dit kan bepaal word deur toepassing van 'n eenvoudige wiskundige formule, wat die uiteindelikke waarde van die projek bereken as die somtotaal van die jaarlikse voordele wat verkry kan word gedurende die leeftyd van die stelsel, min die ontwikkelingskoste. Die formule neem in ag dat die jaarlikse voordeel uit 'n stelsel, bestaande uit verhoogde inligtingswaarde plus 'n afname in dataverwerkingskoste, sal verander as gevolg van veroudering, kapitaalkoste, groeitempo van en leerproses binne, die organisasie.

S.Afr. Tydskr. Bedrytsl. 1984, 15: 144-149

\section{Computer system projects \\ Computer-based systems}

A majority of organizations today are installing computerbased systems, either to replace existing clerical systems such as Invoicing and Debtors Accounting, or to introduce new systems, such as Financial Modelling and Demand Forecasting. that are economically beyond the scope of clerical methods.

These organizations are rarely satisfied with their present collections of computer-based systems. New proposals continually emerge from the various departments, suggesting the development of additional systems or the replacement of existing ones.

\section{Development projects}

Such proposals typically call for system development projects involving a sizeable team of computer specialists for a year or more. These specialists being expensive, an organization cannot usually afford to act on all proposals that are made: Only those that promise very substantial benefits can be allowed to claim the scarce development resources available.

Whenever a system development proposal arises, Data Processing managers, Finance managers, and Line managers serving on Data Processing Steering Committees may be required to decide whether or not a development project will be justified. For this purpose, they may wish to employ a quantitative criterion of project viability.

This article presents concepts of cost, value, and contribution that can be applied in estimating a project's cost and benefit. Then it identifies variations in a system's future contributions - leading to an expression for a project's cumulative benefit. Finally development costs are incorporated, resulting in a formula that enables one to calculate a project's 'net worth', an indicator of its economic viability.

\section{Project costs and benefits \\ Costs and value}

Developing a computer-based system typically demands a project of some magnitude. For example it can take many manmonths or even years to decide what information the computer should produce, to devise appropriate computer files and programs, and to test and implement the system. In the process, the organization usually incurs substantial 'development costs' - in the form of computer specialists' salaries, computer-testing time, user involvement, etc. — over a period of several years.

Once a project has been completed and the new system has become operational, the organization incurs further expenses 
- 'operational costs' such as rental or depreciation on computer hardware and software, terminal operators' salaries, stationery, etc. These costs recur year after year as long as the system remains in operation, and cease only when its outputs are no longer needed or it is replaced with a new improved system.

In parallel with the operational costs, the organization derives 'operational value' from the system - in the form of information that allows it to reduce administration costs, increase liquidity, eliminate risk, etc.

\section{Contribution and benefit}

A worthwhile system ought to yield an annual operational value that more than covers the matching operational costs; indeed the difference between them - the system's annual 'contribution' - should also compensate for the original development costs.

A development project may be of two distinct types. A type 1 project introduces an entirely new 'initial' version of a system, where the organization has had no prior system furmishing the same kind of information. Alternatively a type 2 project replaces a pre-existing clerical - or computer-based - system with an improved 'subsequent' system.

A project of the first type would not be considered economically viable unless the sum of all contributions that the system can be expected to yield during its life span exceeds the total of its development costs. Thus the 'benefit' that should compensate for the development costs is the cumulative worth of the initial system's contributions.

In the case of a project of the second type, the subsequent system's contributions should compensate not only for the development costs, but also for the old system's residual contributions - contributions that could still be gained if it were to continue in operation, but which are lost when it is replaced. Therefore the benefit of such a project consists of the new system's cumulative contributions less the sum of the old system's residual contributions.

\section{Trends in contributions}

\section{Constant contributions}

In order to add up the expected contributions of a new system or the residual contributions of an old one, it is first necessary to establish whether these are likely to increase, decrease, or remain the same over the years.

As a starting point for the analysis, one might assume that a computer-based system remains essentially unchanged from the time of its implementation until it is discontinued or replaced. During the period that it remains in operation, minor modifications may be needed in the form of 'maintenance' - a component of its operating cost. However any major change demands a full-scale development project leading to a subsequent system. Therefore one would expect that a system should generate the same constant contribution year after year, unless other factors intervene.

\section{Obsolescence}

One such factor is obsolescence. As a system ages, its informational output gradually declines in effectiveness - owing to changing needs of its users in the organization, among its customers, suppliers, etc. Consequently its operational value falls.

Furthermore, a system's efficiency is likely to decline with age - as its outmoded design under-utilizes modern computer equipment. Maintenance also becomes more difficult as its basic structure clashes more and more with the demands of a changing environment. Therefore the system's operational costs will rise.

These two operational trends - decreasing value and increasing cost - together result in gradually shrinking contributions. Suppose that the development proposal predicts an annual contribution ' $c$ ': then the first year's contribution will be less than ' $c$ ', the second year's will be even smaller, and so on. For simplicity's sake, let us assume that contributions shrink at a constant rate ' $a$ ' - the system's annual 'obsolescence rate'. Then its actual contribution in the first year would be

$c-c . a=c(1-a)$;

its actual contribution in the second year would be

$c(1-a)-c(1-a) a=c(1-a)^{2}$,

and so on.

\section{Organizational growth}

A second factor is growth. As the organization expands, the number of its customers, suppliers, staff, and transactions increases: Consequently the system's operational costs will escalate. However, organizational growth also enables the system to serve an expanding group of users, and to support decisions involving larger amounts of money. Therefore its operational value should increase too.

Now it is known that mechanized systems in general allow 'economies of scale', so that one can expect costs to escalate less rapidly than value. Therefore contributions should gradually increase. Supposing this happens at an annual growth rate ' $g$ ', then a system's actual contribution $c-c . a$ in its first year of operation would grow by $c . g$ to $c(1-a+g)$; its second contribution would expand to $c(1-a+g)^{2}$; and so on.

\section{Organizational learning}

A third factor is 'organizational learning'. As the organization's personnel gain increasing experience in using the system, they learn to submit input data more efficiently, to use the informational output more effectively, etc. As a result, operational cost should decrease and operational value should increase; consequently the annual contribution should grow as time goes on.

This effect can simply be incorporated in the above formulae by assuming a constant annual rate ' $e$ ' of organizational learning. Then the system's successive contributions would be $c(1-a+e+g)^{1}, c(1-a+e+g)^{2}, c(1-a+e+g)^{3}, \ldots$ etc.

\section{Financial worth of contributions}

\section{The interest factor}

Obsolescence, growth, and learning cause real, measurable variations in a system's annual contributions. Less obviously however, 'financial' considerations demand the recognition of a fourth, imperceptible source of change, resulting from the possibility of earning interest on contributions received.

If each successive annual contribution were invested in a bank, the contribution derived from the first year of the system's operation could be left in the bank for a longer period of time than a contribution obtained towards the end of its life span. Consequently the system's early contributions would earn more interest than the later ones, and accordingly are worth more to the organization.

To quantify this trend, suppose the system has a life span of $n$ years and that contributions earn interest at an annual 
rate ' $i$. Then at the end of the system's life, the first contribution would have been invested for $n-1$ years. and would have grown by a factor $(1+i)^{n-1}$. Similarly the second contribution, having remained in the bank for $n-2$ years, would have grown by the smaller factor $(1+i)^{r+1}$. Therefore the 'terminal values' of the system's contributions - at the end of its life span - would be

$c(1-a+e+g)(1+i)^{n-1}, c(1-a+e+g)^{2}(1+i)^{n-1}, \ldots$ etc.

\section{The discount factor}

However, terminal values are not directly comparable with development costs. The latter are incurred towards the beginning of a system's life span - and if invested in a bank at the time the system is implemented - would have grown by a factor $(1+i)^{n}$ after $n$ years. For compatibility, terminal values of contributions therefore need to be reduced to 'present values' at implementation time. This can be done by asking 'What amount $P$, invested at implementation time, would grow in $n$ years to an amount $F$ that equals the terminal value?' Inverting the well-known compound interest formula $F=P(1+i)^{n}$, one finds that

$P=F \div(1+i){ }^{n}$

In other words, terminal values should be divided by the factor $(1+i)^{n}$ to discount them to equivalent present values. Accordingly a system's first contribution would discount to

$c(1-a+e+g)(1+i)^{n-1} \div(1+i)^{n}$,

or simply

$c(1-a+e+g) \div(1+i)$.

Similary the second contribution reduces to

$c((1-a+e+g) \div(1+i)]^{2}$,

and so on ...

\section{The impact of inflation}

\section{Shrinking yardstick}

Inflation, like growth and obsolescence, is a further factor causing perceptible variations in a system's annual contributions. When operational values and costs are measured with the contracting yardstick of an inflating currency, they will increase over the years. Therefore future contributions, when actually measured in the currencies of the times at which they are received, will be considerably larger than

$c(1-a+e+g) \div(1+i), c(1-a+e+g) \div(1+i)]^{2}, \ldots$,

which are expressed in the earlier currency of the project proposal. Accordingly one might argue that each of these formulae should be multiplied by an appropriate 'inflation factor'.

But if this were done, then the inflated formulae would express the various contributions in terms of different future currencies. They could not then be added to each other, nor could they be compared with the development costs estimated by the project proposal in today's currency. To standardize currencies, each formula would then have to be divided by a 'deflation factor'. Except in rare cases where inflation affects costs and values differently, this equals and therefore cancels the inflation factor. Consequently inflation normally requires no explicit recognition in a system's future contributions.

\section{Cost of capital}

Yet inflation does have an indirect, implicit effect on the in- terest and discount factors. To formulate this impact, suppose an investment $\boldsymbol{P}$ were deposited in a bank on the first day of 1982 , allowed to accumulate interest for a year, and then withdrawn with interest $P . i$ on the first day of 1983. Apparently, the investment has grown in value from $P$ to $P(1+i)$. However, the bank received $P$ in the currency of 1982 but repaid $P(1+i)$ in the inflated currency of 1983 ! At an annual inflation rate $j$, the exchange rate between 1982 and 1983 currencies is $1: 1+j$. So $P(1+l)$ is actually only worth

$P(1+i) \div(1+j)$

in terms of 1982 currency. In other words, the investment $P$ has only increased in real value by $(1+i) \div(1+j)$. This therefore is the real interest factor.

But as prevailing interest rates offered by banks today seldom exceed the corresponding inflation rate, $1+i$ is approximately the same as $1+j$ and the real interest factor is an ineffectual 1 , if contributions were invested in a bank. However, suppose they were instead re-invested in the organization itself.

Now most organizations offer internal rates of return that are considerably higher than the external rate of return which a bank can afford to give its customers. Therefore if contributions are re-invested, $(1+i) \div(1+j)$ substantially exceeds 1 . Indeed the Theory of Corporate Finance suggests that

$(1+i) \div(1+j)=1+k$,

where $k$ is the organization's 'deflated cost of capital'. Consequently a system's annual contributions can simply be expressed as

$c[(1-a+e+g) \div(1+k)]^{1}, c[(1-a+e+g) \div(1+k)]^{2}, \ldots$ etc.

\section{Cumulative worth of contributions}

\section{Declining contributions}

Each successive annual contribution can now be seen as the project proposal's estimate ' $c$ ', multiplied by increasing powers of a composite factor $(1-a+e+g) \div(1+k)$. Examining this factor more closely, one observes that the obsolescence rate ' $a$ ' largely cancels out the effects of the growth rate ' $g$ ' and learning rate ' $e$ '. Therefore the predominant impact of the composite factor is that of its divisor $(1+k)$. Consequently one would expect that each successive contribution is typically less than the previous one.

This effect can be formalized by defining the system's 'annual rate of decline' as

$r=(1+k) \div(1-a+e+g)-1$.

Then the factor $(1-a+e+g) \div(1+k)$ transforms into $1 \div(1+r)$, and the system's successive contributions can be expressed more realistically as

$c \div(1+r)^{1}, c \div(1+r)^{2}, \ldots c \div(1+r)^{n}$.

\section{Cumulative worth}

A system's cumulative contribution during its $n$-year life-span would therefore be

$W=c \div(1+r)^{1}+c \div(1+r)^{2}+\ldots+c \div(1+r)^{n}$.

To obtain a more compact formula for a series of this kind, one multiplies each term in this equation by $(1+r)$ :

$$
W+r W=c+c \div(1+r)^{1}+\ldots+c \div(1+r)^{n-1} \text {. }
$$

The two equations are then subtracted from each other; the middle terms on the right hand side cancelling one another, 
leaving

$r W=c-c \div(1+r)^{n}$.

Dividing by $r$, this yields the simple annuity formula

$$
W=c\left[1-(1+r)^{-n}\right] \div r \text {. }
$$

\section{Benefit of a project}

\section{Alternative project types}

A development project would not normally be justified unless the resulting system is likely to yield a benefit large enough to compensate for its development costs. In the case of a type 1 project - one that implements an initial system where the organization has no equivalent prior system - the benefit is the cumulative worth of the new system's contributions, namely

$B=c\left[1-(1+r)^{-n}\right] \div r$

Alternatively for a type 2 project - which replaces an old system with a subsequent new one - the benefit consists of the new system's cumulative contributions, less the sum of all the contributions still potentially obtainable from the old system, but lost when it is replaced. Suppose the development proposal estimates the current contribution of the old system as ' $f$, and that its contributions decline at the same rate $r$ as the new system. Then the old system would still be capable of delivering $n$ 'residual' contributions:

$f \div(1+r)^{1}, f \div(1+r)^{2}, \ldots f \div(1+r)^{n}$

which collectively add up to

$f\left[1-(1+r)^{-n}\right] \div r$

Therefore a type 2 project's benefit would be

$B=(c-f)\left[1-(1+r)^{-n}\right] \div r$.

\section{Annual benefit}

These two alternative benefit formulae differ only in their leading terms: $c$ for type $1,(c-f)$ for type 2 . The latter, $(c-f)$, represents the increase in a system's contribution when it is upgraded by implementing a subsequent version. But the former, $c$, also represents an increase in contribution from 0 when there was no system of that kind, to $c$ when the initial system is implemented. The two terms can therefore be unified in one concept, ' $b$ ', the increase in contribution. This allows the two alternative benefit formulae to be combined into a single expression for a project's 'cumulative benefit':

$B=b\left[1-(1+r)^{-n}\right] \div r$

Reversing the argument which led to the formula for $W, B$ can now be seen as the sum of the terms

$B=b \div(1+r)^{1}+b \div(1+r)^{2} \ldots b \div(l+r)^{n}$

These represent the annual increases in a system's contributions attributable to the development project - declining at an annual rate $r$. The factor $b$ can therefore be interpreted as the project's 'annual benefit'. Bearing in mind that contribution consists of operational value less operational cost, $b$, the increase in contribution, can be expressed as

$b=$ increase in operational value + decrease in operational cost.
Therefore a project's annual benefit derives from two separate components:

- The enhanced value of the system's informational outputs;

- the reduction in the system's data processing cost.

\section{Net worth of a project}

\section{Project cost}

To assess a project's economic viability, its cumulative benefit $B$ needs to be compared with the total of its development costs. Suppose the project takes $m$ years to complete and that it absorbs a development cost $d_{1}$ in the first year, $d_{2}$ in the second, etc. These costs represent investments in the new system investments which yield no tangible returns until it is finally implemented. In the interim the organization loses the interest it might have gained if $d_{1}, d_{2}$ etc. had been invested elsewhere, or incurs interest charges on the capital raised in order to make these investments. Thus interest on the development costs constitute additional costs of the project.

Regarding $d_{1}$ as an investment made at the beginning of the first year of work on the project, the organization pays or loses interest at an annual rate $k$, compounded for $m$ years. This increases the cost of the first year's work from $d$ to $d$ $(1+k)^{m}$. Similarly the second year's work, involving $m-1$ years' interest, actually costs $d_{2}(1+k)^{m-1}$.

Therefore at implementation time the project's costs add up to

$D=d_{1}(1+k)^{m}+\ldots+d_{m}(1+k)^{l}$.

\section{Net worth}

For a project to be considered economically viable, the total cost $D$ incurred up to the time the system is implemented should be less than $B$, the cumulative worth of its future benefits discounted back to the time of implementation. Therefore a criterion that determines whether a system will be viable or nonviable is the condition $D<B$.

However, this condition does not indicate how viable the project will be. To get a more useful criterion, it can be transformed into $B-D>0$. Now the difference $B-D$, being the cumulative worth of benefits less costs, can be regarded as the project's 'net worth'

$N=B-D$.

A large value of $N$ means that the project will yield considerably more benefit than its cost, and indicates a high degree of viability; alternatively if $N$ is small, the benefit is not much more than the cost, and implies only marginal viability. Therefore the criterion

$N>0$

not only distinguishes between viability and nonviability, but also serves as a measure of the project's degree of viability.

\section{Viability criterion}

\section{Quantitative appraisal}

When Data Processing managers, Financial managers, or Line managers serving on Data Processing Steering Committees receive a development proposal, they can now decide whether to institute a project or reject the proposal by evaluating the formulae:

Net worth $\quad N=B-D$

Total cost $\quad D=d_{1}(1+k)^{m}+\ldots+d_{m}(1+k)^{1}$ 
$\begin{array}{ll}\text { Total benefit } & B=b\left[1-(1+r)^{-n}\right] \div r \\ \text { Decline rate } & r=(1+k) \div(1-a+e+g)-1\end{array}$

From estimates of the 'parameters'

$\begin{array}{ll}d_{1}, d_{2} \ldots= & 1 s t, 2 \text { nd, . . year's development cost, } \\ m & =\text { duration of the project, } \\ n & =\text { life span of the system, } \\ b & =\text { increase in the system's operational value } \\ & \text { plus decrease in its data processing cost, } \\ \boldsymbol{a} & =\text { system's annual obsolescence rate, } \\ \boldsymbol{k} & =\text { organization's annual cost of capital, } \\ \boldsymbol{e} & =\text { organization's annual rate of learning, } \\ \boldsymbol{g} & =\text { organization's annual growth rate. }\end{array}$

An illustration

Suppose an organization grows at 5\%, learns at $3 \%$, and incurs capital costs at $11 \%$ per annum. It is considering a development proposal which calls for a 2-year project costing R60 000 in the first year and R70 000 in the second. This is intended to replace an old clerical system which costs R30 000 per annum and produces information valued at $R 40000$ per annum. The new computer-based system is expected to cost $R 20000$ per annum and produce information valued at R50 000 per annum; its obsolescence rate is $12 \%$ per annum, and its life expectancy is 8 years. In this case:

$$
\begin{aligned}
& r=(1+0,11) \div(1-0,12+0,03+0,05)-1=0,16 \\
& b=(50000-20000)-(40000-30000)=20000 \\
& B=20000\left[1-(1+0,16)^{-8}\right] \div 0,16=86872 \\
& D=60000(1+0,11)^{2}+70000(1+0,11)=151626 \\
& N=86872-151626=-64754
\end{aligned}
$$

Consequently one concludes that the project is definitely not economically viable.

\section{The acceptance decision}

\section{Limitations}

Although the above formulae were established by precise mathematical deduction, it does not follow that the answers they yield will be equally accurate. One reason is that the parameters $d, m, n$, etc., are subject to errors of estimation - errors that are propagated by the formulae into the resulting conclusion about the system's viability or nonviability. As these can never entirely be eliminated, there is always some risk of drawing the wrong conclusion. This risk is negligible when $N$ is large - negative or positive - in relation to $D$; but is appreciable when $N$ is small.

A second reason for caution is that the formulae are based on a number of simplifying assumptions - such as uniform rates of growth and obsolescence, a constant cost of capital, etc. - which may be inappropriate in particular situations. Therefore even if the parameters $a, g, e, k$, etc., were estimated with absolute accuracy, disparities between the assumed and actual variations in a system's future contributions will cause corresponding errors in the net worth predicted by the formulae. Again, such errors are immaterial when $N$ is large, but can easily lead to a wrong conclusion when $N$ is small.

\section{Marginal projects}

If the formulae predict a cumulative benefit $B$ which substantially exceeds the corresponding development $\operatorname{cost} D$, and therefore yield a large value of $N$, the decision-maker need not hesitate in accepting the project. However, what should he do when $N$ is small and he faces the risk of a wrong decision?

In the case of this kind of 'marginal' project, he can take four alternative courses of action. The easiest and safest of these is simply to reject the proposal. However, such a negative approach is rarely in the organization's best interest - particularly when a promising-looking project yields an unexpectedly low net worth. Consequently the decision-maker might consider three more positive courses of action.

In the first of these, he might recognize the results of the formulae as too inconclusive, either for acceptance or rejection of the proposal. Accordingly he would seek additional, qualitative, deciding factors - for example the attitudes of the personnel who are to use the proposed system, the system's impact on the organization's public image, and so forth.

A second possible course of action is to initiate a costaccounting study of the proposed system's anticipated costs, value, and contributional variations in the hope of establishing more accurate parameters and more appropriate formulae. This approach is particularly recommended in the case of very expensive or unusual systems.

Thirdly, the decision-maker could refer the proposal back to its originators with a request to find modifications that might yield a more significant value of $N$. As 'necessity is the mother of invention', they might well find ways of reducing the system's costs without substantially sacrificing values - leading to decreases in $D$ and increases in $B$ that could double or treble the value of $N$. For example, a ruthless purge of a proposed system's more esoteric informational outputs and data inputs can often yield considerable savings in operational costs and enormous savings in development cost. Similarly development cost can frequently be reduced to a fraction of the original estimate by compromising the desired informational output with the actual outputs available from an existing 'package', and buying the system ready-made from a software vendor.

\section{Sensitivity analysis}

A useful preliminary step in an attempt to increase a marginal project's net worth is 'sensitivity analysis'. This involves changing each individual parameter, for example by $1 \%$, and recalculating $N$ according to the above formulae. Then by comparing the corresponding changes in $N$, one can find out which parameter has the greatest impact on net worth. Knowing which parameter is 'critical' in the proposal can then help focus the search for modifications on aspects of the project that are likely to yield the greatest improvements in its net worth.

\section{Conclusion}

\section{Simple calculations}

In conclusion, it appears that the net-worth formulae offer a comfortably rational approach to the often nerve-racking decision whether or not to develop a proposed system. Furthermore, they can even help convert a marginal project into a viable one. All one needs to do is estimate a few parameters, enter them into a pocket calculator, press a few buttons, and out pops the answer. Indeed, if one owns a financial calculator, even the formidable-looking cumulative-benefit formula can be evaluated merely by pressing a single button.

It seems too simple to be true.

\section{Underlying problems}

\section{It is too simple to be true!}

Computer-based systems have been introduced too recently in mankind's history, and are still in too-rapid a state of evolution for people to estimate the parameters $a, b, e, g, k$, and 
$n$ with any degree of confidence. Nor do we have sufficient experience with computer-based systems to prove beyond reasonable doubt that obsolescence, growth, etc. will usually cause the same rate of contributional change in every year of a system's operation.

Therefore, while entering the parameters into the calculator, one should realize that these are mere approximations; when adding, subtracting, multiplying and dividing them in accordance with the formulae, one should be aware that these operations too are mere approximations. Finally when the net worth appears, one should see it not as an absolutely reliable measure, but as a prediction - a mere forecast - of the project's probable worth. In short, one should treat the result with a healthy scepticism.

This does not imply, however, that one should reject it outright. In an uncertain world, even an 'educated guess' is a more reliable basis for decision-making than mere 'gut feel'. 